Journal of Advanced Research in Fluid Mechanics and Thermal Sciences

\title{
Magnetohydrodynamic Flow of Micropolar Fluid and Heat Transfer Between a Porous and a Non-Porous Disk
}

\author{
Ashwini Bhat ${ }^{1}$, Nagaraj N Katagi ${ }^{1,{ }^{*}}$ \\ 1 Department of Mathematics, Manipal Institute of Technology, MAHE, Manipal, India
}

\begin{tabular}{|c|c|}
\hline ARTICLE INFO & ABSTRACT \\
\hline $\begin{array}{l}\text { Article history: } \\
\text { Received } 2 \text { June } 2020 \\
\text { Received in revised form } 6 \text { July } 2020 \\
\text { Accepted } 7 \text { July } 2020 \\
\text { Available online } 15 \text { September } 2020\end{array}$ & $\begin{array}{l}\text { This paper presents a study of the MHD flow of micropolar fluid and also heat transfer } \\
\text { between porous disk and a non-porous disk of infinite radii. The non-zero tangential } \\
\text { slip velocity is considered at the porous disk. The self-similar ODEs are obtained using } \\
\text { the Von-Karman similarity transformation from the governing PDEs. The resulting } \\
\text { equations are then solved numerically by a very efficient Keller-box method based on } \\
\text { a finite-difference scheme. The influence of various pertaining parameters on velocity, } \\
\text { micro-rotation, temperature, skin friction, and couple stress coefficient have been } \\
\text { analyzed. The obtained results agree well with the available literature for special cases. } \\
\text { The analysis finds that the heat transfer rate at the surfaces of the disks increases with } \\
\text { the increase in the Reynolds number, the magnetic parameter, and the Prandtl } \\
\text { number. The shear stresses decrease with the increase in the injection while increase } \\
\text { with the increase in the applied magnetic field. }\end{array}$ \\
\hline
\end{tabular}

Keywords:

MHD flow; micropolar fluid; Slip velocity; Keller-box method; heat transfer; porous disk

Copyright @ 2020 PENERBIT AKADEMIA BARU - All rights reserved

\section{Introduction}

In the past few decades, due to the wide range of applications of fluids that have their own internal structures and ability to rotate about their own axis imposed the modeling of theory for micro-fluids. The rotation of an individual particle is coupled with the macroscopic velocity field describes these micropolar fluids. A well-defined and effective theory for micropolar fluids was proposed by Eringen [1]. The unique natural structure of the elements in micropolar fluids makes them an excellent model for different engineering and biological fluids. Ariman et al., [2,3] have reviewed various applications of these micropolar fluids. Guram and Anwar [4] analyzed the flow of micropolar fluids due to a rotating disk with uniform suction and injection using numerical methods and compared with known results for a Newtonian fluid. Kelson and Desseaux [5] derived a perturbation solution for the self-similar flow of micropolar fluid driven by a stretching sheet with

\footnotetext{
* Corresponding author.

E-mail address:nn.katagi@manipal.edu
}

https://doi.org/10.37934/arfmts.75.2.5978 
uniform suction and injection. Subsequently, they used the same analysis to investigate the twodimensional flow of this fluid in a porous channel [6]. Many other research workers have successfully extended this model to a wide range of applications including flow in capillaries, micro-channels, and porous media. A useful account of the micro-polar theory and extensive literature can be found in the book by Lukaazewicz [7].

Characteristics of magnetic field effects have significant applications in science and engineering such as Magnetohydrodynamics pumps, geothermal energy extraction, MHD generators, and many more. A useful review of MHD theory and its applications can be found in the book by Moreau [8]. Many researchers have reviewed the effects of heat transfer and magnetic field on the flow of micropolar fluid with various flow geometries such as vertical plates, stretching sheets, channels, tubes, and disks. The analysis of MHD laminar flow between two parallel porous disks for large suction Reynolds number was carried out by Rudraiah and Chandrashekara [9] using the perturbation technique. Attia [10] obtained the numerical solution for the problem of steady flow and heat transfer of a conducting fluid in a rotating non-conducting infinite porous disk in the presence of an external magnetic field and ion slip. Many investigations can be witnessed in the literature on MHD fluid flows under different flow situations of fluid between disks.

The study of disk flows with micro-structure has received more attention in recent years due to its major industrial applications in the fields of lubrication, heat and mass exchange, biomechanics, rotating machinery, and many more. Viscous heat dissipation in fluid flows is a remarkable area of analysis which is usually difficult to integrate into the mathematical model of the flow as it increases the complexity of the problem. However, in the literature, numerous ways of mathematical models are proposed to understand the heat transfer analysis for different flow situations. The problem of steady viscous fluid flow between parallel porous disk was numerically investigated by Rasmussen [11] for different values of suction and injection. Later, Elcart [12] has obtained similar solutions for non-rotational fluid motion between porous disk with uniform arbitrary suction and injection. A numerical simulation for the problem of micropolar fluid flow between a rotating and a stationary disk was obtained by Guram and Anwar [13]. Further, they also performed an analysis of micropolar fluid flow due to a rotating disk in which at the surface of the disk the flow was driven with uniform suction and injection [14]. The studies were validated by providing a comparison of the results for micropolar and Newtonian fluids. Numerous models and methods can be seen in the open literature that explains the flow between porous/ nonporous with rotating/stationary disks. Takhar et al., [15] obtained a finite element solution for the micropolar fluid flow and heat transfer between two porous disks. Finite difference solution for the asymmetric flow of micropolar fluid in a porous channel with different wall permeability was given by Ashraf et al., [16]. Wehgal [17] discussed the MHD asymmetric flow of electrically conducting fluid flow between porous disks. Later, the flow of micropolar fluid between orthogonally moving porous disks was analyzed by Si et al., [18] using Homotopy based analytical method. Vatani et al., [19] and Valipour et al., [20] carried out an analysis of micropolar fluid flow between disks using optimal homotopy analysis method and compared the solution with numerical results obtained using the R-K method. Subsequently, Hasnain and Abbas [21] reported the entropy generation analysis on the mixed convective two-phase flow of micropolar and nanofluid in an inclined channel. Abbas et al., [22] also obtained the asymptotic solutions for the flow of Casson fluid between parallel discs, executing in-plane motion in different manners.

Most of the above studies are confined to zero-slip boundary conditions. But, the experimental findings of Beavers and Joseph [23], and Saffman [24] revealed the existence of slip velocity at the porous bounding surface that alters the fluid motion. Abbas et al., [25] asymptotically analyzed MHD viscous fluid flow due to a rotating disk and a radially stretching-shrinking disk with Navier slip conditions. Recently, they also gave an analytical solution for the flow of a nanofluid in a vertical 
porous channel with velocity slip and thermal radiation [26]. MHD slip Darcy flow of viscoelastic fluid over a stretching surface in a porous medium with thermal radiation and viscous dissipation is analytically examined by Wahid et al., [27]. The main objective of the present investigation is to analyze the heat transfer and effects external magnetic field on the non-Newtonian micropolar fluid flow between a porous and a non-porous disk by incorporating velocity slip conditions at the porous boundary. The governing partial differential equations are reduced to a system of coupled non-linear ordinary differential equations by introducing suitable similarity transformations due to Von-Karman. Since the resultant equation is highly nonlinear, we employ the efficient finite difference based numerical method named Keller-box scheme for the computation of the pertinent results. The box technique is a powerful tool for solutions of nonlinear differential equations [28-31].

\section{Mathematical Formulation of the Problem}

Consider the axisymmetric laminar steady incompressible flow of an electrically conducting micropolar fluid between parallel disks of infinite radii separated by a distance of $2 l$, lower one being impermeable and the upper disk is porous as shown in Figure 1. At the disk boundaries a uniform transverse magnetic field of strength $B_{0}$ is applied. And assuming a stationary magnetic field $B$ in the transverse direction, which is perpendicular to the velocity field lying in the $r z$-plane. We neglect the induced magnetic field when compared to imposed field. It is also assumed that there is no applied electric field, i.e., $E=0$. With all the above assumptions, the linearized form of electromagnetic body force can be written as $-\sigma_{e} B_{0}{ }^{2} V$, where $\sigma_{e}$ is electrical conductivity of fluid. The governing equations for MHD laminar viscous incompressible steady flow of micropolar fluid are

$$
\begin{aligned}
& \frac{\partial u}{\partial r}+\frac{u}{r}+\frac{1}{l} \frac{\partial w}{\partial \eta}=0 \\
& \rho\left(u \frac{\partial u}{\partial r}+\frac{w}{l} \frac{\partial u}{\partial \eta}\right)=(\mu+k)\left(\frac{\partial^{2} u}{\partial r^{2}}+\frac{1}{r} \frac{\partial u}{\partial r}-\frac{u}{r^{2}}+\frac{1}{l^{2}} \frac{\partial^{2} u}{\partial \eta^{2}}\right)-\frac{\kappa}{h} \frac{\partial N}{\partial \eta}-\frac{\partial p}{\partial r}-\sigma_{e} B_{0}^{2} u \\
& \rho\left(u \frac{\partial w}{\partial r}+\frac{w}{l} \frac{\partial w}{\partial \eta}\right)=(\mu+\kappa)\left(\frac{\partial^{2} w}{\partial r^{2}}+\frac{1}{r} \frac{\partial w}{\partial r}+\frac{1}{l^{2}} \frac{\partial^{2} u}{\partial \eta^{2}}\right)-\kappa\left(\frac{\partial N}{\partial r}+\frac{N}{r}\right)-\frac{1}{l} \frac{\partial p}{\partial \eta} \\
& \rho j\left(u \frac{\partial N}{\partial r}+\frac{w}{l} \frac{\partial N}{\partial \eta}\right)=\gamma\left(\frac{\partial^{2} N}{\partial r^{2}}+\frac{1}{r} \frac{\partial N}{\partial r}-\frac{N}{r^{2}}+\frac{1}{l^{2}} \frac{\partial^{2} N}{\partial \eta^{2}}\right)+\kappa\left(\frac{1}{l} \frac{\partial u}{\partial \eta}-\frac{\partial w}{\partial r}\right)-2 \kappa N \\
& \nabla \cdot B=0 \\
& \nabla \times B=\mu_{m} J \text { where, } J=\sigma_{e}(E+V \times B) \\
& \nabla \times E=0
\end{aligned}
$$

where $\eta=\frac{z}{l}$ is similarity variable, $\rho, \mu$ are the density and kinematic viscosity, $j$ is the microinertia viscosity, $\kappa, \gamma$ are the microrotation parameter and spin gradient viscosity respectively, $J$ is current density, $\mu_{m}$ is the magnetic permeability, $E$ is the electric field, $B$ is the total magnetic field. 


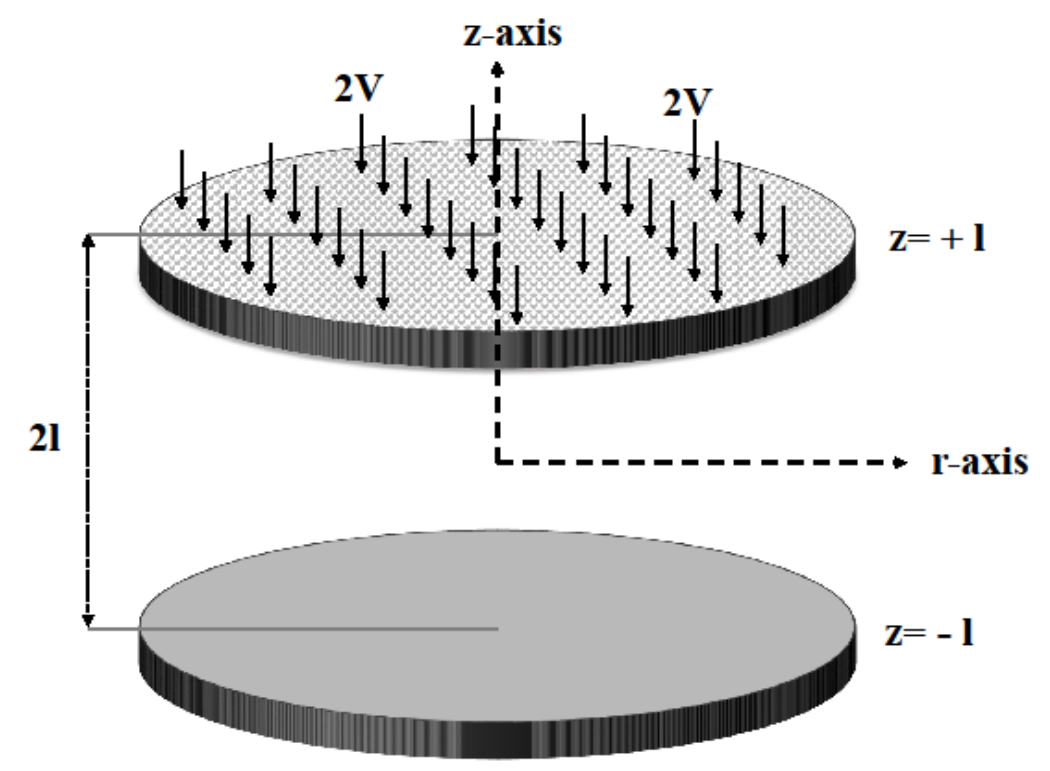

Fig. 1. Geometry of the problem

A constant velocity of magnitude $2 \mathrm{~V}$ is injected through the upper disk while the lower disk is impermeable. Assuming velocity slip boundary condition at the upper permeable disk, the velocity and microrotation field at the two disks can be written as

$$
\begin{aligned}
& u(r,-l)=u_{\text {slip }} ; \quad u(r, l)=0 \\
& w(r,-l)=0 ; \quad w(r, l)=2 V \\
& N(r, \pm l)=0
\end{aligned}
$$

where, $u_{\text {slip }}=-\frac{\sqrt{k}}{\alpha}\left(\frac{\partial u}{\partial r}\right)$ is the slip velocity following BJ conditions [23]. Neglecting the viscous dissipation, the equation for temperature field can be written as

$$
\rho c_{p}\left(u \frac{\partial T}{\partial r}+\frac{w}{l} \frac{\partial T}{\partial \eta}\right)-\kappa_{0}\left(\frac{1}{l^{2}} \frac{\partial T}{\partial \eta^{2}}+\frac{\partial T}{\partial r^{2}}+\frac{1}{r} \frac{\partial T}{\partial r}\right)=0
$$

where $T$ is the temperature, $c_{p}$ is the specific heat at constant pressure and $\kappa_{0}$ is the thermal conductivity of fluid. The boundary conditions for temperature field can be written as [4],

$T= \begin{cases}T_{1}, & \eta=-1 \\ T_{2}, & \eta=1\end{cases}$

Using Von-Karman's similarity transformations [32] given below,

$$
\begin{aligned}
& u=\frac{V r}{l} f^{\prime}(\eta), \quad w=-2 V f(\eta), \\
& N=\frac{V r}{l^{2}} g(\eta), \quad \theta(\eta)=\frac{T-T_{1}}{T_{2}-T_{1}} .
\end{aligned}
$$


The continuity Eq. (1) is satisfied with these transformations, thus representing a possible fluid motion. Substituting (11) in Eq. (1)-(3) and (10), eliminating the pressure terms, the governing equations reduces to

$$
\begin{aligned}
& (1+R) f^{\prime \prime \prime \prime}+\operatorname{Re}\left(f f^{\prime \prime \prime}-M^{2} f^{\prime \prime}\right)-R g^{\prime \prime}=0 \\
& c g^{\prime \prime}-A \operatorname{Re}\left(\frac{1}{2} f^{\prime} g-f g^{\prime}\right)+R\left(f^{\prime \prime}-2 g\right)=0 \\
& \theta^{\prime \prime}+\operatorname{Re} \operatorname{Pr} f \theta^{\prime}=0
\end{aligned}
$$

where $R e=\frac{\rho 2 V l}{\mu}$ is the Reynolds number, $M^{2}=\frac{\sigma_{e} l B_{0}^{2}}{\rho 2 V}$ is the magnetic parameter, $\operatorname{Pr}=\frac{\mu c_{p}}{\kappa_{0}}$ is the Prandtl number, $R=\frac{\kappa}{\mu}, A=\frac{j}{l^{2}}, c=\frac{\gamma}{\mu l^{2}}$ are the micropolar parameters respectively named vortex viscosity parameter, microinertia density parameter and spin gradient viscosity parameter.

The boundary conditions in (9) and (11) takes the dimensionless form as,

$$
\left\{\begin{array}{l}
f(-1)=0, f^{\prime}(-1)=0, g(-1)=0, \theta(-1)=0 \\
f(1)=1, f^{\prime}(1)=-\phi f^{\prime \prime}(1), g(1)=0, \theta(1)=1
\end{array}\right.
$$

The shear and couple stresses on the disk are defined, respectively, as

$$
\begin{aligned}
& \tau_{\omega}=-\left.(\mu+\kappa) \frac{\partial u}{\partial z}\right|_{z= \pm l}=-\mu(1+R) \frac{r V}{l^{2}} f^{\prime \prime}( \pm 1) \\
& m_{\omega}=-\left.\gamma \frac{\partial N}{\partial z}\right|_{z= \pm l}=-\gamma \frac{r V}{l^{3}} g^{\prime}( \pm 1)
\end{aligned}
$$

We have to solve the system of equations in Eq. (12)-(14) subject to slip boundary conditions represented in (15). It can be noted that Eq. (12)-(13) reduce to the corresponding equations obtained in our previous work [33] in the absence of the external magnetic field, i.e., $M=0$. These facts validate our model for the micropolar fluid motion in the presence of the external magnetic field.

\section{Method of Solution}

We seek solution of the governing problem which is a coupled non-linear differential equation by using an efficient numerical scheme called box scheme. Further solution is analyzed for various pertinent micropolar parameters $A, R, c$, Magnetic parameter $M$, Prandtl number $\operatorname{Pr}$ and Reynolds number $R e$.

\subsection{Keller-Box Method}

This method is initialized by introducing new variables as,

$$
u=f^{\prime}, v=f^{\prime \prime}, w=f^{\prime \prime \prime}, h=g^{\prime}
$$


The coupled system of equations can thus be rewritten as six set of first order differential equations in terms of these new variables as given below.

$$
\begin{aligned}
f^{\prime} & =u ; u^{\prime}=v ; v^{\prime}=w ; g^{\prime}=h ; \theta^{\prime}=t \\
w^{\prime} & =\frac{R}{1+R} h^{\prime}-\frac{R e}{1+R}\left(f w-M^{2} v\right) \\
h^{\prime} & =-\frac{R}{c}(v-2 g)+\frac{A R e}{c}\left(\frac{1}{2} u g-f h\right) \\
t^{\prime} & =-\operatorname{RePrft}
\end{aligned}
$$

The corresponding boundary conditions in terms of new variables are,

at $\eta=-1, f=0, u=0, \quad g=0, \quad \theta=0$

at $\eta=1, f=1, u=-\varphi v, g=0, \quad \theta=1$

Following this step, the system of first order equations are now discretized by substituting the appropriate finite difference approximations. The system Eq. (19) can be written as,

$$
\begin{aligned}
& f_{j}-f_{j-1}=d_{j}\left(u_{j}+u_{j-1}\right) \\
& u_{j}-u_{j-1}=d_{j}\left(v_{j}+v_{j-1}\right) \\
& v_{j}-v_{j-1}=d_{j}\left(w_{j}+w_{j-1}\right) \\
& g_{j}-g_{j-1}=d_{j}\left(h_{j}+h_{j-1}\right) \\
& \theta_{j}-\theta_{j-1}=d_{j}\left(t_{j}+t_{j-1}\right) \\
& w_{j}-w_{j-1}=\frac{R}{1+R}\left(h_{j}-h_{j-1}\right)-\frac{d_{j} \operatorname{Re}}{2(1+R)}\left(f_{j}+f_{j-1}\right)\left(w_{j}+w_{j-1}\right)+\frac{d_{j} \operatorname{ReM} M^{2}}{1+R}\left(v_{j}+v_{j-1}\right) \\
& h_{j}-h_{j-1}=\frac{d_{j} A R e}{4 c}\left(u_{j}+u_{j-1}\right)\left(g_{j}+g_{j-1}\right)-\frac{d_{j} A R e}{2 c}\left(f_{j}+f_{j-1}\right)\left(h_{j}+h_{j-1}\right)-\frac{d_{j} R}{c}\left(v_{j}+v_{j-1}\right)+\frac{2 d_{j} R}{c}\left(g_{j}+g_{j-1}\right) \\
& t_{j}-t_{j-1}=\frac{-\operatorname{RePr} d_{j}}{2}\left(f_{j}-f_{j-1}\right)\left(t_{j}+t_{j-1}\right)
\end{aligned}
$$

This nonlinear discretized system is linearized using Newton's linearisation method. Substituting Newton's iterations as, ()$_{j}^{(i+1)}=()_{j}^{(i)}+\delta()_{j}^{(i)}$ for all the variables in the system, we obtain the following linear set of algebraic equations.

$$
\begin{aligned}
& \delta f_{j}-\delta f_{j-1}-d_{j}\left(\delta u_{j}+\delta u_{j-1}\right)=\left(r_{1}\right)_{j} \\
& \delta u_{j}-\delta u_{j-1}-d_{j}\left(\delta v_{j}+\delta v_{j-1}\right)=\left(r_{2}\right)_{j}
\end{aligned}
$$




$$
\begin{aligned}
& \delta v_{j}-\delta v_{j-1}-d_{j}\left(\delta w_{j}+\delta w_{j-1}\right)=\left(r_{3}\right)_{j} \\
& \delta g_{j}-\delta g_{j-1}-d_{j}\left(\delta h_{j}+\delta h_{j-1}\right)=\left(r_{4}\right)_{j} \\
& \delta \theta_{j}-\delta \theta_{j-1}-d_{j}\left(\delta t_{j}+\delta t_{j-1}\right)=\left(r_{5}\right)_{j}
\end{aligned}
$$

$\left(a_{1}\right)_{j} \delta w_{j}+\left(a_{2}\right)_{j} \delta w_{j-1}+\left(a_{3}\right)_{j}\left(\delta h_{j}-\delta h_{j-1}\right)+\left(a_{4}\right)_{j}\left(\delta f_{j}+\delta f_{j-1}\right)+\left(a_{5}\right)_{j}\left(\delta v_{j}-\delta v_{j-1}\right)=$ $\left(r_{6}\right)_{j}$

$\left(b_{1}\right)_{j} \delta h_{j}+\left(b_{2}\right)_{j} \delta h_{j-1}+\left(b_{3}\right)_{j}\left(\delta g_{j}+\delta g_{j-1}\right)+\left(b_{4}\right)_{j}\left(\delta u_{j}+\delta u_{j-1}\right)+\left(b_{5}\right)_{j}\left(\delta f_{j}+\delta f_{j-1}\right)+$

$\left(b_{4}\right)_{j}\left(\delta u_{j}+\delta u_{j-1}\right)+\left(b_{5}\right)_{j}\left(\delta f_{j}+\delta f_{j-1}\right)+\left(b_{6}\right)_{j}\left(\delta v_{j}+\delta v_{j-1}\right)=\left(r_{7}\right)_{j}$

$c_{1} \delta \theta_{j}+c_{2} \delta \theta_{j-1}+c_{3}\left(\delta f_{j}+\delta f_{j-1}\right)=\left(r_{8}\right)_{j}$

where,

$$
\begin{aligned}
& \left(a_{1}\right)_{j}=1+\frac{d_{j} R e}{2(1+R)}\left(f_{j}+f_{j-1}\right) \\
& \left(a_{2}\right)_{j}=-2+\left(a_{1}\right)_{j} \\
& \left(a_{3}\right)_{j}=\frac{-R}{1+R} \\
& \left(a_{4}\right)_{j}=-\frac{d_{j} R e}{2(1+R)}\left(w_{j}+w_{j-1}\right) \\
& \left(a_{5}\right)_{j}=\frac{-d_{j} R e M^{2}}{2(1+R)} \\
& \left(b_{1}\right)_{j}=1+\frac{d_{j} A R e}{2 c}\left(f_{j}+f_{j-1}\right) \\
& \left(b_{2}\right)_{j}=-2+\left(b_{1}\right)_{j} \\
& \left(b_{3}\right)_{j}=\frac{-A R e d_{j}}{4 c}\left(u_{j}+u_{j-1}\right)-\frac{2 d_{j} R}{c} \\
& \left(b_{4}\right)_{j}=\frac{-A R e d_{j}}{4 c}\left(g_{j}+g_{j-1}\right) \\
& \left(b_{5}\right)_{j}=\frac{d_{j} A R e}{2 c}\left(h_{j}+h_{j-1}\right) \\
& \left(b_{6}\right)_{j}=\frac{d_{j} R}{c} \\
& \left(c_{1}\right)_{j}=1+\frac{\text { RePrd }_{j}}{2}\left(f_{j}+f_{j-1}\right) \\
& \left(c_{2}\right)_{j}=-2+\left(c_{1}\right)_{j}
\end{aligned}
$$


$\left(c_{3}\right)_{j}=\frac{-\operatorname{PrRed}_{j}}{2}\left(t_{j}+t_{j-1}\right)$

$\left(r_{1}\right)_{j}=d_{j}\left(u_{j}+u_{j-1}\right)+f_{j-1}-f_{j}$

$\left(r_{2}\right)_{j}=d_{j}\left(v_{j}+v_{j-1}\right)+u_{j-1}-u_{j}$

$\left(r_{3}\right)_{j}=d_{j}\left(w_{j}+w_{j-1}\right)+v_{j-1}-v_{j}$

$\left(r_{4}\right)_{j}=d_{j}\left(h_{j}+h_{j-1}\right)+g_{j-1}-g_{j}$

$\left(r_{5}\right)_{j}=d_{j}\left(t_{j}+t_{j-1}\right)+\theta_{j-1}-\theta_{j}$

$\left(r_{6}\right)_{j}=w_{j-1}-w_{j}+\frac{R}{1+R}\left(h_{j}-h_{j-1}\right)-\frac{d_{j} R e}{2(1+R)}\left(f_{j}+f_{j-1}\right)\left(w_{j}+w_{j-1}\right)+\frac{d_{j} R e M^{2}}{1+R}\left(v_{j}+v_{j-1}\right)$

$\left(r_{7}\right)_{j}=h_{j-1}-h_{j}+\frac{R e A d_{j}}{4 c}\left(u_{j}+u_{j-1}\right)\left(g_{j}+g_{j-1}\right)-\frac{d_{j} A R e}{2 c}\left(f_{j}+f_{j-1}\right)\left(h_{j}+h_{j-1}\right)-\frac{R d_{j}}{c}\left(v_{j}+\right.$ $\left.v_{j-1}\right)+\frac{2 d_{j} R}{c}\left(g_{j}+g_{j-1}\right)$

$\left(r_{8}\right)_{j}=\frac{-R e P r d_{j}}{2}\left(f_{j}+f_{j-1}\right)\left(t_{j}+t_{j-1}\right)-t_{j}+t_{j-1}$

The linearized system of Eq. (29)-(36) have a block tri-diagonal structure which can be solved with the help of block elimination method. In vector -matrix form, Eq. (29)-(36) can be written as,

$A \delta=r$

where,

$$
A=\left[\begin{array}{ccccccc}
{\left[A_{1}\right]} & {\left[C_{1}\right]} & \cdots & \cdots & \cdots & & \\
\vdots & {\left[A_{2}\right]} & {\left[C_{2}\right]} & \cdots & & & \\
\vdots & \vdots & \vdots & \ddots & & & \\
\vdots & \vdots & \vdots & \ddots & & & \\
& & & \ddots & & & \\
\cdots & & \cdots & \cdots & {\left[B_{J-1}\right]} & {\left[A_{J-1}\right]} & {\left[C_{J-1}\right]} \\
\cdots & & \cdots & \cdots & \cdots & {\left[B_{J}\right]} & {\left[A_{J}\right]}
\end{array}\right], \delta=\left[\begin{array}{c}
{\left[\delta_{1}\right]} \\
{\left[\delta_{2}\right]} \\
\vdots \\
{\left[\delta_{J-1}\right]} \\
{\left[\delta_{J}\right]}
\end{array}\right] r=\left[\begin{array}{c}
{\left[r_{1}\right]} \\
{\left[r_{2}\right]} \\
\vdots \\
{\left[r_{J-1}\right]} \\
{\left[r_{J}\right]}
\end{array}\right]
$$

where the elements are defined by, 


$$
\begin{aligned}
& {\left[A_{j}\right]=\left[\begin{array}{cccccccc}
0 & 0 & 0 & 0 & 1 & -d_{j} & 0 & 0 \\
-d_{j} & 0 & 0 & 0 & 0 & 1 & 0 & 0 \\
-1 & -d_{j} & 0 & 0 & 0 & 0 & 0 & 0 \\
0 & 0 & -d_{j} & 0 & 0 & 0 & 1 & 0 \\
0 & 0 & 0 & -d_{j} & 0 & 0 & 0 & 1 \\
\left(a_{5}\right)_{j} & \left(a_{2}\right)_{j} & -\left(a_{3}\right)_{j} & 0 & \left(a_{4}\right)_{j} & 0 & 0 & 0 \\
\left(b_{6}\right)_{j} & 0 & \left(b_{2}\right)_{j} & 0 & \left(b_{5}\right)_{j} & \left(b_{4}\right)_{j} & \left(b_{3}\right)_{j} & 0 \\
0 & 0 & 0 & \left(c_{2}\right)_{j} & \left(c_{3}\right)_{j} & 0 & 0 & 0
\end{array}\right], \quad 1 \leq j \leq J-1} \\
& {\left[A_{J}\right]=\left[\begin{array}{cccccccc}
0 & 0 & 0 & 0 & 0 & 0 & 0 & 0 \\
-d_{J} & 0 & 0 & 0 & -d_{J} & 0 & 0 & 0 \\
-1 & -d_{J} & 0 & 0 & 1 & -d_{J} & 0 & 0 \\
0 & 0 & -d_{J} & 0 & 0 & 0 & -d_{J} & 0 \\
0 & 0 & 0 & -d_{J} & 0 & 0 & 0 & -d_{J} \\
\left(a_{5}\right)_{J} & -\left(a_{2}\right)_{J} & -\left(a_{3}\right)_{J} & 0 & \left(a_{5}\right)_{J} & \left(a_{1}\right)_{J} & \left(a_{3}\right)_{J} & 0 \\
\left(b_{6}\right)_{J} & 0 & \left(b_{2}\right)_{J} & 0 & \left(b_{6}\right)_{J} & 0 & \left(b_{1}\right)_{J} & 0 \\
0 & 0 & 0 & \left(c_{2}\right)_{J} & 0 & 0 & 0 & \left(c_{1}\right)_{J}
\end{array}\right]} \\
& {\left[B_{j}\right]=\left[\begin{array}{cccccccc}
0 & 0 & 0 & 0 & -1 & d_{j} & 0 & 0 \\
0 & 0 & 0 & 0 & 0 & -1 & 0 & 0 \\
0 & 0 & 0 & 0 & 0 & 0 & 0 & 0 \\
0 & 0 & 0 & 0 & 0 & 0 & -1 & 0 \\
0 & 0 & 0 & 0 & 0 & 0 & 0 & -1 \\
0 & 0 & 0 & 0 & \left(a_{4}\right)_{j} & 0 & 0 & 0 \\
0 & 0 & 0 & 0 & \left(b_{5}\right)_{j} & \left(b_{4}\right)_{j} & \left(b_{3}\right)_{j} & 0 \\
0 & 0 & 0 & 0 & \left(c_{3}\right)_{j} & 0 & 0 & 0
\end{array}\right], 2 \leq j \leq J}
\end{aligned}
$$$$
\left[C_{j}\right]=\left[\begin{array}{cccccccc}
0 & 0 & 0 & 0 & 0 & 0 & 0 & 0 \\
-d_{j} & 0 & 0 & 0 & 0 & 0 & 0 & 0 \\
1 & -d_{j} & 0 & 0 & 0 & 0 & 0 & 0 \\
0 & 0 & -d_{j} & 0 & 0 & 0 & 0 & 0 \\
0 & 0 & 0 & -d_{j} & 0 & 0 & 0 & 0 \\
\left(a_{5}\right)_{j} & \left(a_{1}\right)_{j} & \left(a_{3}\right)_{j} & 0 & 0 & 0 & 0 & 0 \\
\left(b_{6}\right)_{j} & 0 & \left(b_{1}\right)_{j} & 0 & 0 & 0 & 0 & 0 \\
0 & 0 & 0 & \left(c_{1}\right)_{j} & 0 & 0 & 0 & 0 \\
& & & & & & &
\end{array}\right], 1 \leq j \leq J-1
$$

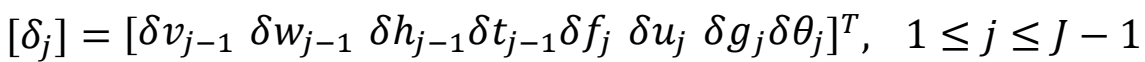


and

$\left[\delta_{J}\right]=\left[\begin{array}{lll}\delta v_{J-1} & \delta w_{J-1} \delta h_{J-1} \delta t_{J-1} \delta v_{J} \delta w_{J} \delta h_{J} \delta t_{J}\end{array}\right]^{T}$

$\left[r_{j}\right]=\left[\left(r_{1}\right)_{j}\left(r_{2}\right)_{j}\left(r_{3}\right)_{j}\left(r_{4}\right)_{j}\left(r_{5}\right)_{j}\left(r_{6}\right)_{j}\left(r_{7}\right)_{j}\left(r_{8}\right)_{j}\right]^{T}, \quad 1 \leq j \leq J$

Now we write,

$A=L u$

where,

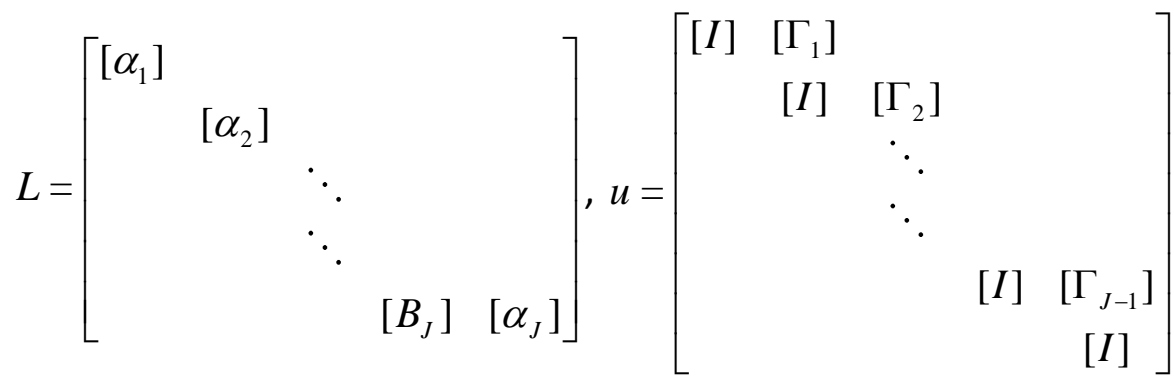

Here, $[I]$ is unit matrix and $\left[\alpha_{i}\right]$ and $\left[\Gamma_{i}\right]$ are $8 \times 8$ matrices whose elements are determined by the following equations

$\left[\alpha_{j}\right]=\left[A_{1}\right]$

$\left[A_{1}\right]\left[\Gamma_{1}\right]=\left[C_{1}\right]$

$\left[\alpha_{j}\right]=\left[A_{j}\right]-\left[B_{j}\right]\left[\Gamma_{j-1}\right], \quad j=2,3,, J$

$\left[\alpha_{j}\right]\left[\Gamma_{j}\right]=\left[C_{j}\right], \quad j=2,3,, J-1$

Eq. (61) substituted in (58) and we have,

$L u \delta=r$

Defining $u \delta=w$, we have, $L w=r$, where,

$w=\left[\left[w_{1}\right]\left[w_{2}\right]\left[w_{3}\right]\left[w_{4}\right]\left[w_{5}\right]\left[w_{6}\right]\left[w_{7}\right]\left[w_{8}\right]\right]^{T}$

and the $\left[w_{j}\right]$ are $8 \times 1$ column matrices. The elements $w$ can be solved as,

$\left[\alpha_{1}\right]\left[w_{1}\right]=\left[r_{1}\right]$

$\left[\alpha_{j}\right]\left[w_{j}\right]=\left[r_{j}\right]-\left[B_{j}\right]\left[w_{j-1}\right]$

Once the elements of $w$ are found, solution for $\delta$ can be obtained using relations 


$$
\begin{aligned}
& {\left[\delta_{J}\right]=\left[w_{J}\right]} \\
& {\left[\delta_{j}\right]=\left[w_{j}\right]-\left[\Gamma_{j}\right]\left[\delta_{j+1}\right]}
\end{aligned}
$$

Theses solution for $\delta$ can be used to find $(i+1)^{t h}$ iteration.

\section{Results and Discussion}

In the present study we investigated the influence of uniform magnetic field on the characteristics of flow and heat transfer of micropolar fluid flow between parallel disks of infinite radii, lower one being impermeable and a porous disk at the upper side. We also considered the presence of velocity slip at the porous boundary which effects the flow along with Reynolds number, micropolar parameters, Prandtl number, and magnetic parameter. It is observed that the two micropolar characteristics $A$ and $c$ have a negligible effect on velocity and temperature profiles. Therefore, their values are fixed at $A=1, c=2$ in the entire analysis. The present results are in excellent agreement with the published literature results given by Ashraf et al., [34] in the absence of magnetic field and slip.

Figure 2 represents the variations in dimensionless profiles of axial velocity, radial velocity, microrotation and temperature for Reynolds number $R e \in[0,100]$. Axial velocity is observed to increase with an increase in the magnitude of Reynolds number in the presence of slip. It typically varies from 0 at the lower impermeable disk to 1 at the upper porous disk. Radial velocity profiles are increasing with an increase in Reynolds number near the impermeable disk. Whereas, the profiles were decreasing with an increase in the magnitude of Reynolds number as the permeable disk is reached. The flow is perfectly symmetric for $R e=0$. The magnitude of microrotation is found to decrease with an increase in Reynolds number near the impermeable disk and a reverse trend is observed near the porous disk. In the dimensionless form of temperature field, an increase from 0 to 1 is observed with an increase in suction Reynolds number. The profile is linear for zero Reynolds number.

The effect of magnetic parameter $M$ on different flow characteristics with other parameters fixed at $R=10, R e=20, \varphi=0.1$ and $\operatorname{Pr}=0.3$ can be visualized in Figure 3 . With an increase in magnetic parameter, it is seen that the axial velocity profiles are increasing near the impermeable disk and are decreasing in magnitude near the porous disk. The radial velocity profiles become flattered as $M$ increases. It is also noticed that as the magnetic parameter increases the boundary layer thickness decreases. The microrotation profiles are positive in the first half and are negative in the second half region, which shows a reverse rotation near the boundaries. As the magnetic parameter is increased the microrotation profiles decreases, this fact can be used in lubrication problems, where the induced magnetic field can be controlled to obtain desirable angular rotations. The effect of an increase in micropolar parameter $R$ is to decrease axial velocity profiles near the impermeable disk but no remarkable changes are observed at the porous disk.

The radial velocity profiles being parabolic in nature increases with increase in $R$ near impermeable boundary, but decreased near permeable disk as shown in Figure 4. A significant influence of $R$ is observed on microrotation profiles. $R=0$ corresponds to the case of Newtonian fluids. For other cases the microrotation increases with increase in micropolar parameter $R$. This parameter is observed to have no effect on dimensionless temperature profiles. The dimensionless temperature are thus plotted for typical values of Prandtl number $\mathrm{Pr}$. The increase in $\mathrm{Pr}$ value results in an increase in temperature profiles reaching absolute value of 1 . 
Figure 5 represent fluctuations in dimensionless axial velocity, radial velocity, microrotation and temperature for different values of velocity slip coefficient $\varphi$. With an increase in slip coefficient, the dimensionless axial velocity profiles are found to decrease in magnitude. Similarly, the dimensionless radial velocity profiles show an increase initially near impermeable disk but decreases as porous disk is approached for an increase in slip coefficient. The microrotation profiles increases near the porous disk for an increase in slip coefficient whereas no significant changes are observed near the nonporous disk. Also, a slight decrease in the temperature profiles is seen for an increase in slip coefficient.

The influence of Reynolds number $R e$ on shear stress and couple stress are depicted in Figure 6 and 7. It is verified that at the lower disk shear stress $f^{\prime \prime}$, couple stress $g^{\prime}(-1)$ and heat transfer rate $\theta^{\prime}(-1)$ increases with increase in Reynolds number. But, an opposite behavior is noticed near the porous disk. The heat transfer rate at permeable disk approaches to zero as $R e \rightarrow \infty$.

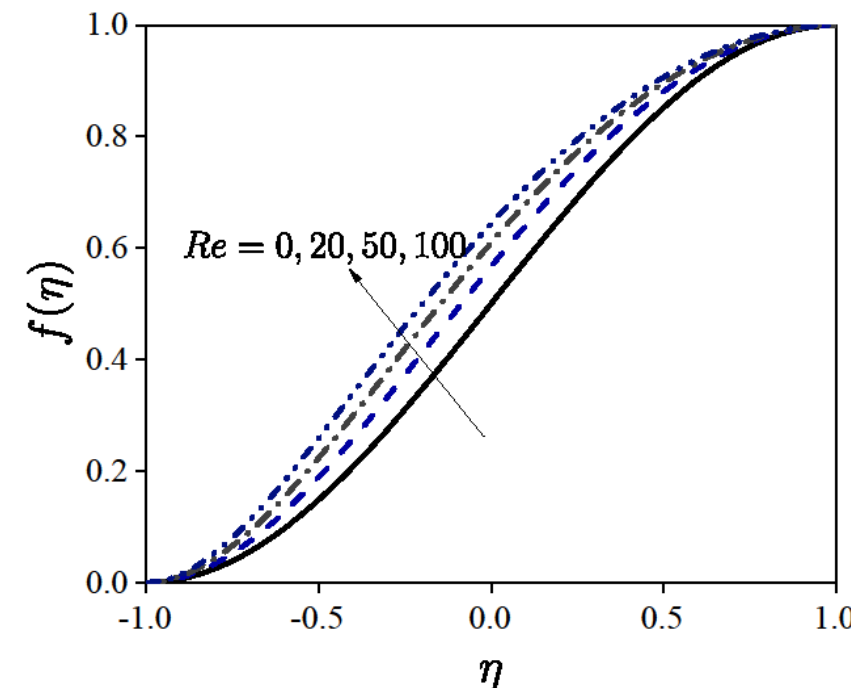

(a)

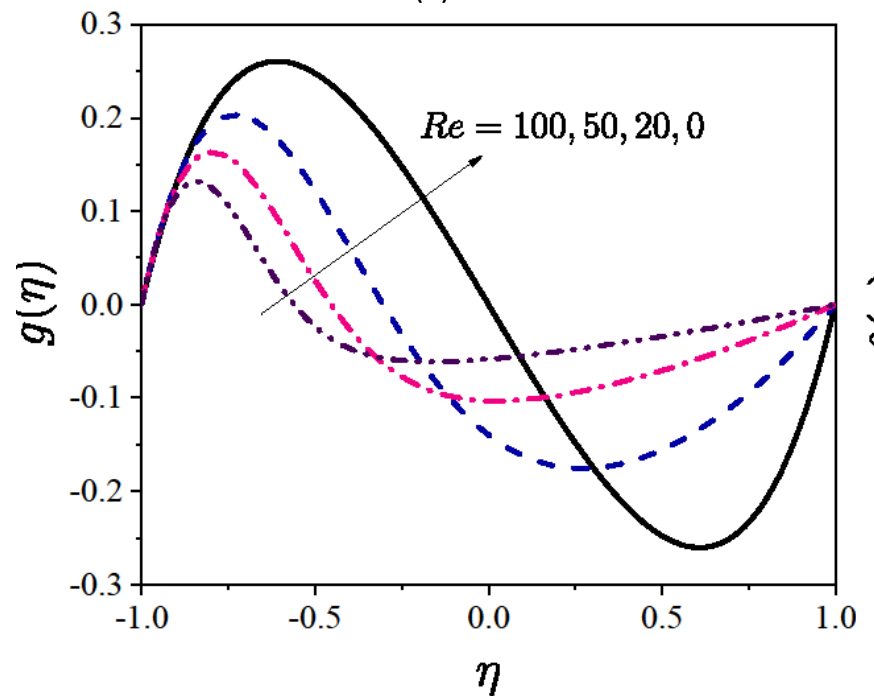

(c)

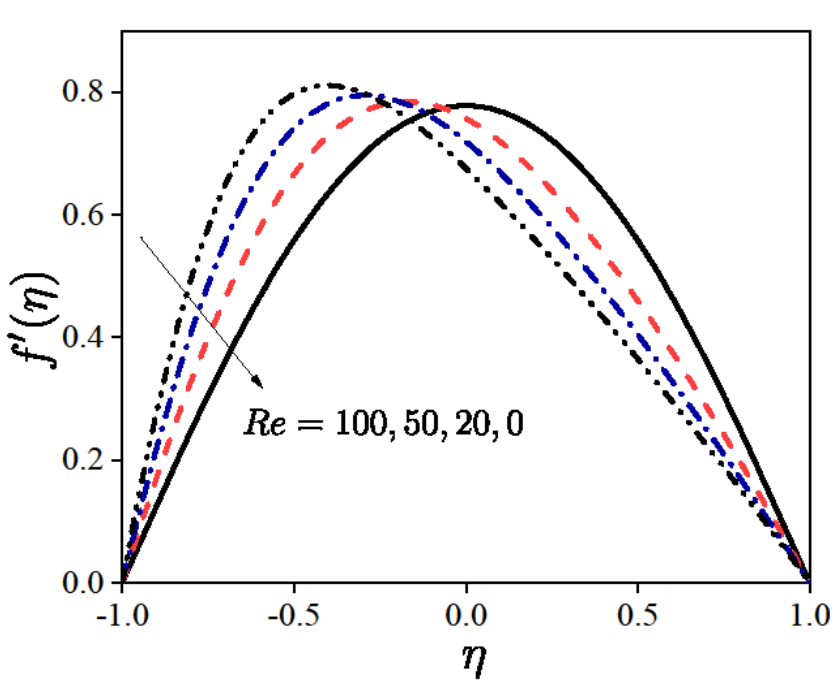

(b)

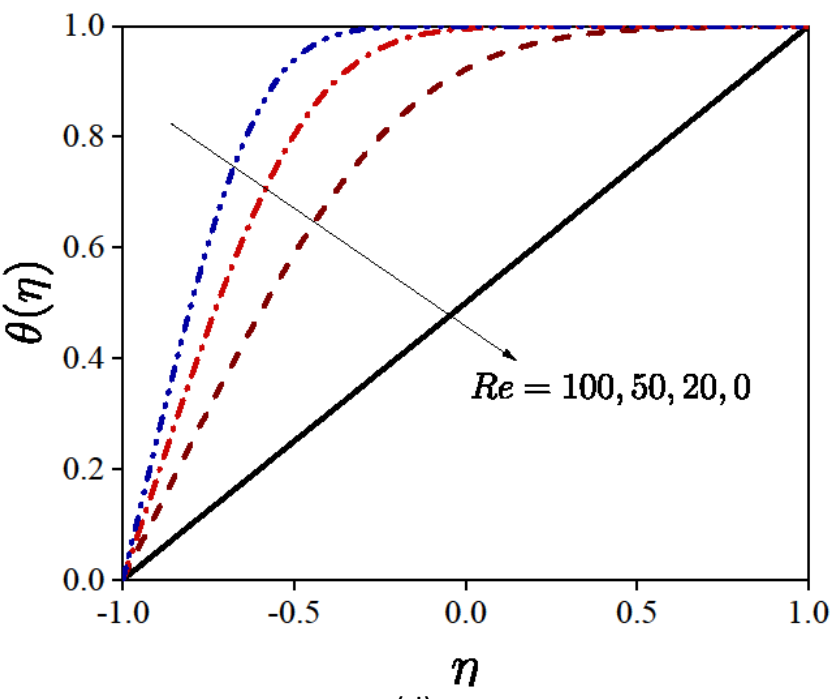

(d)

Fig. 2. Dimensionless (a) Axial velocity, (b) Radial velocity, (c) Microrotation and (d) Temperature profiles for various Reynolds number with $R=10, M=0.5$ and $P r=0.3$ 


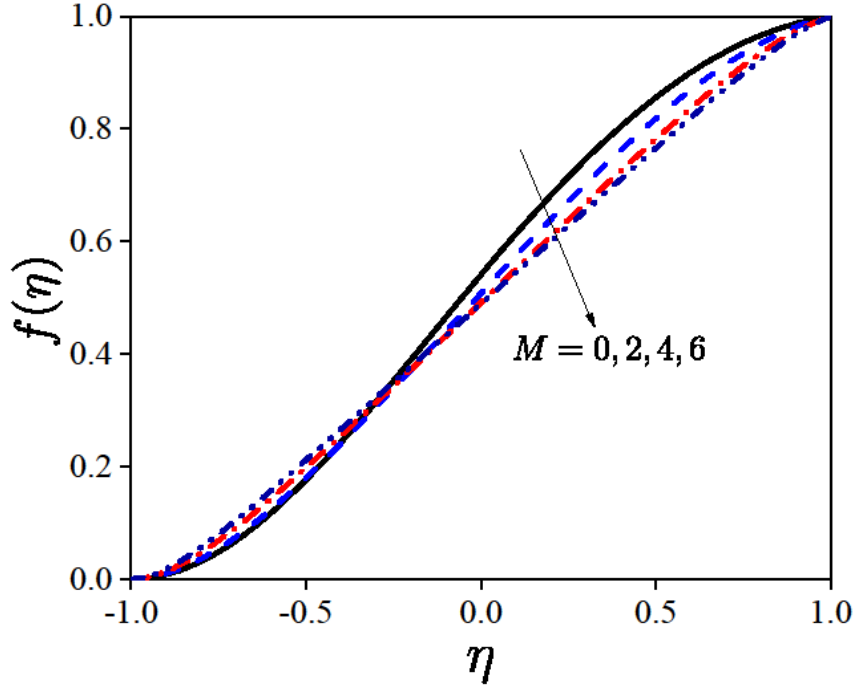

(a)

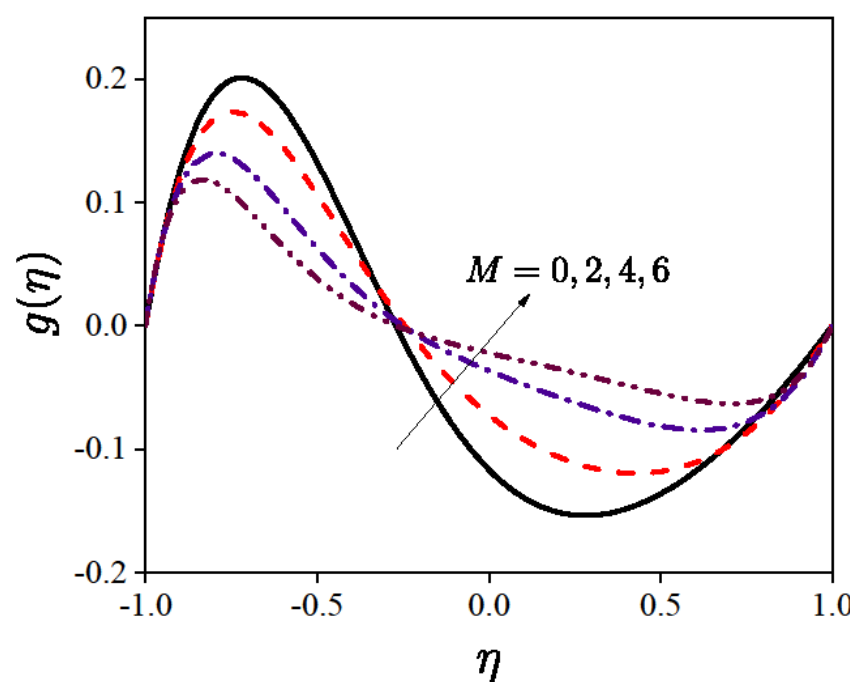

(c)

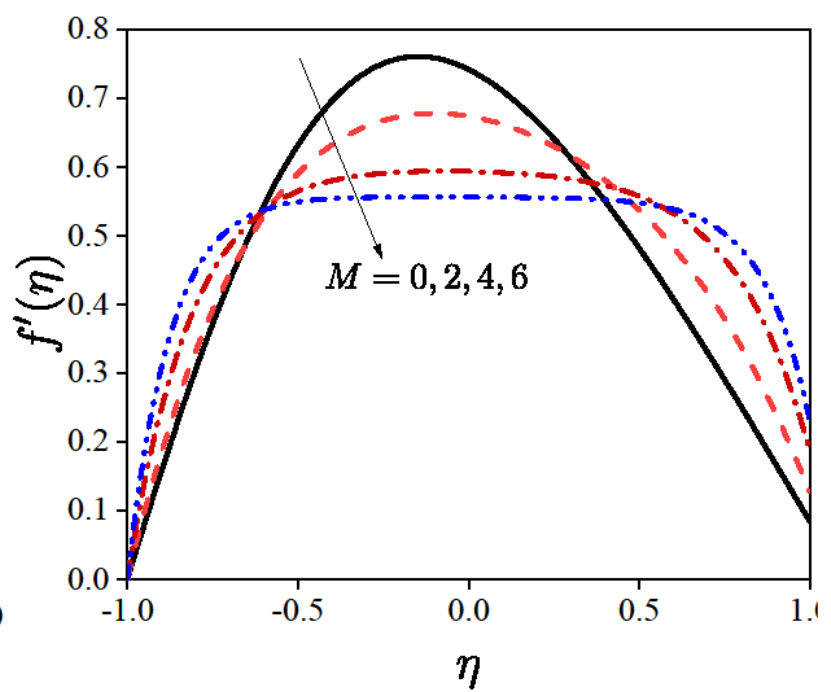

(b)

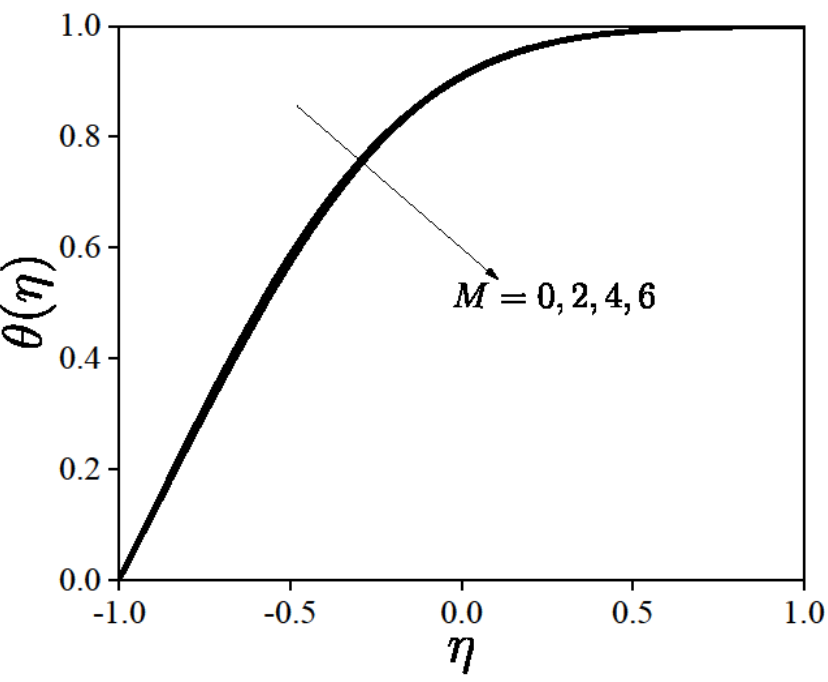

(d)

Fig. 3. Dimensionless (a) Axial velocity, (b) Radial velocity, (c) Microrotation and (d) Temperature profiles for various magnetic parameter with $R=10, \operatorname{Re}=20, \varphi=0.1$ and $\operatorname{Pr}=0.3$

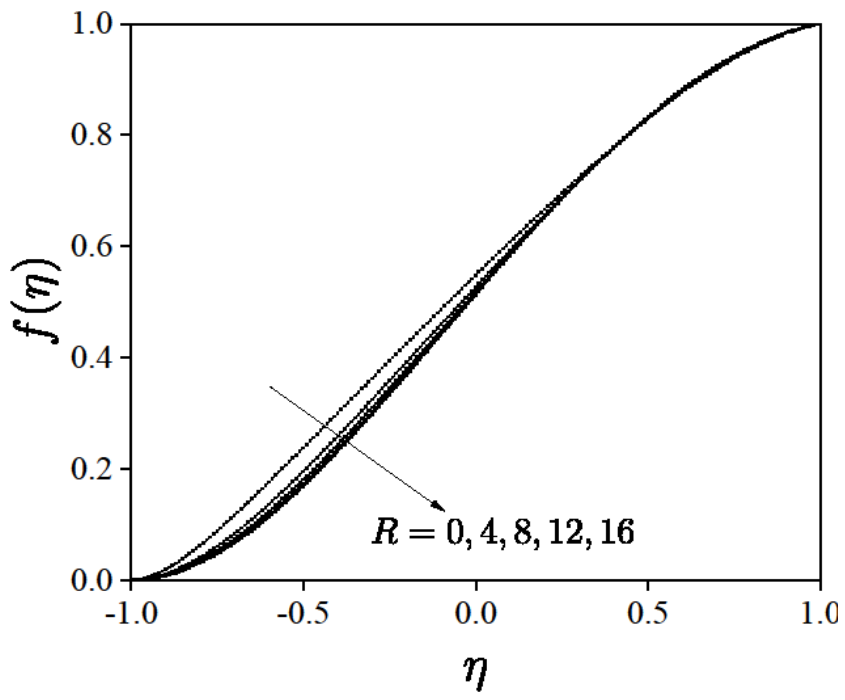

(a)

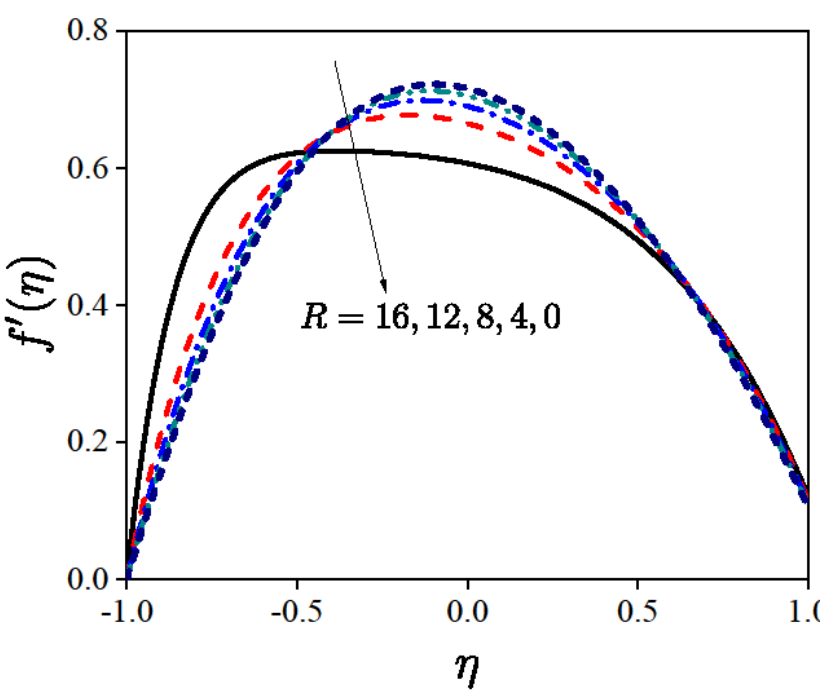

(b) 


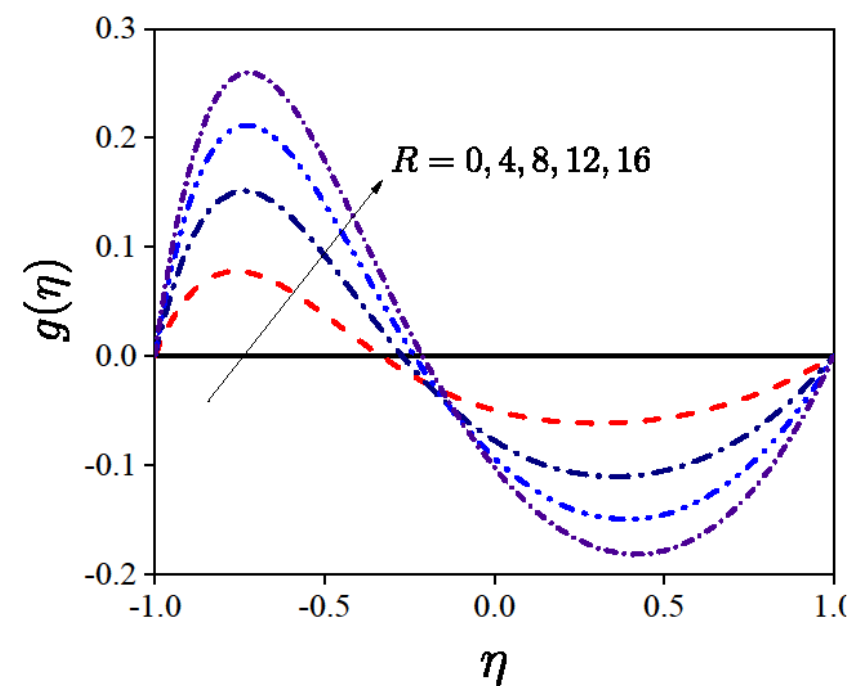

(c)

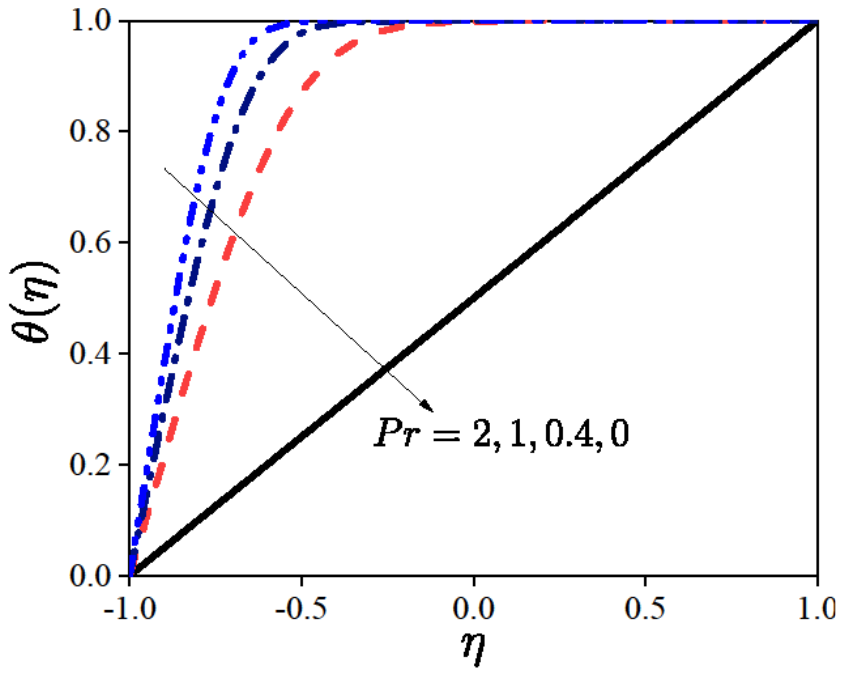

(d)

Fig. 4. Dimensionless (a) Axial velocity, (b) Radial velocity, (c) Microrotation for various micropolar parameter $(R)$ and (d) Temperature profile for different Prandtl number $(\operatorname{Pr})$ with $\operatorname{Re}=20, M=1.5, \varphi=$ 0.1 and $\operatorname{Pr}=0.3$

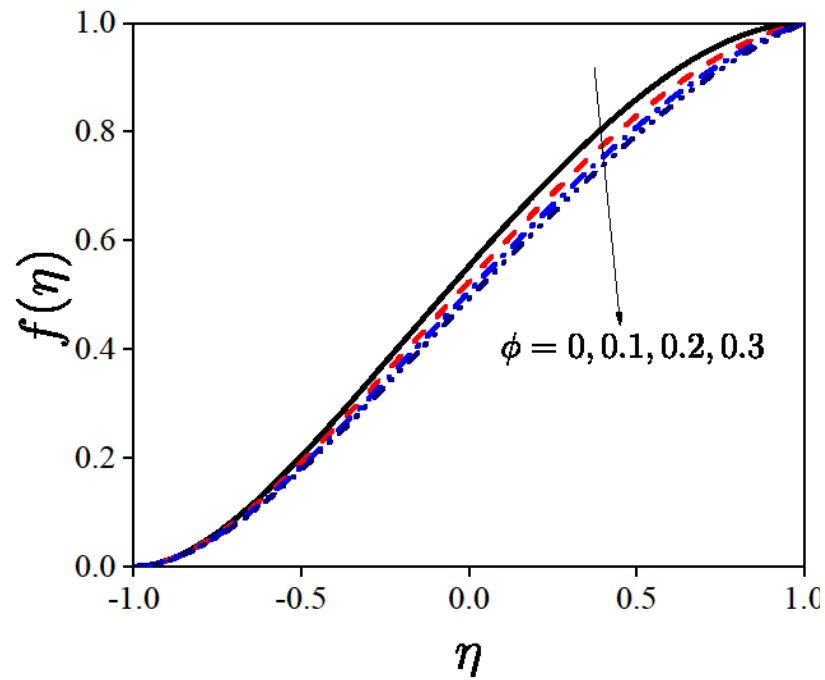

(a)

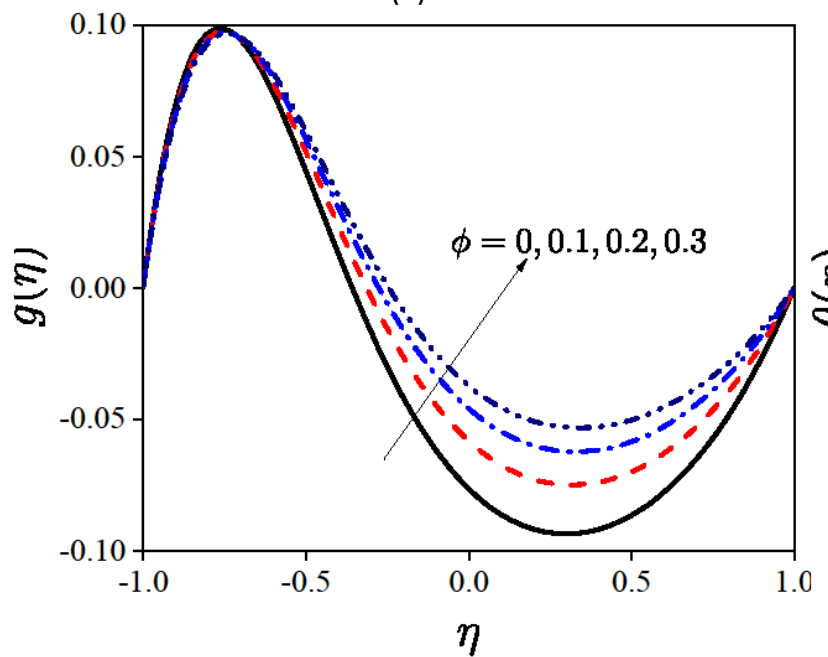

(c)

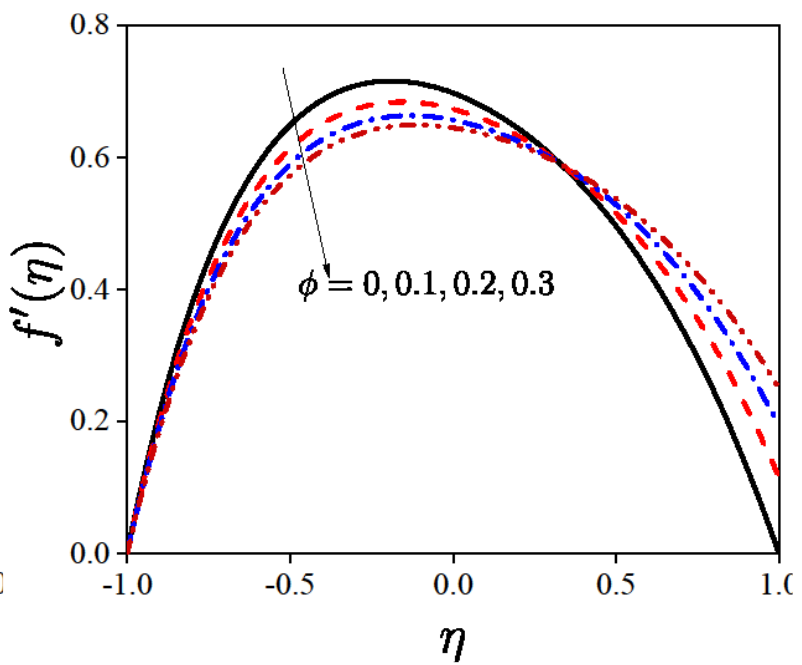

(b)

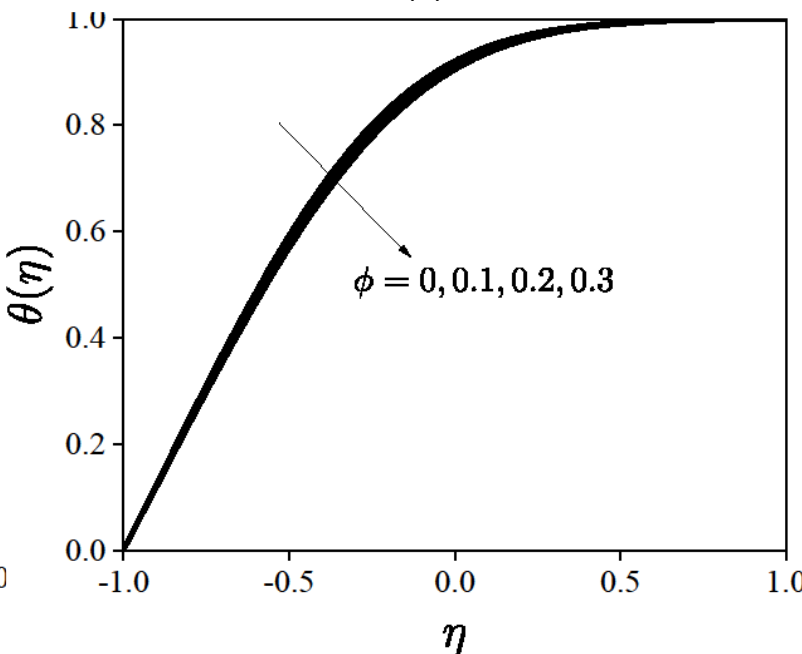

(d)

Fig. 5. Dimensionless (a) Axial velocity, (b) Radial velocity, (c) Microrotation and (d) Temperature profiles for various slip coefficient $(\varphi)$ with $R=5, R e=20, M=1.5$ and $\operatorname{Pr}=0.3$ 


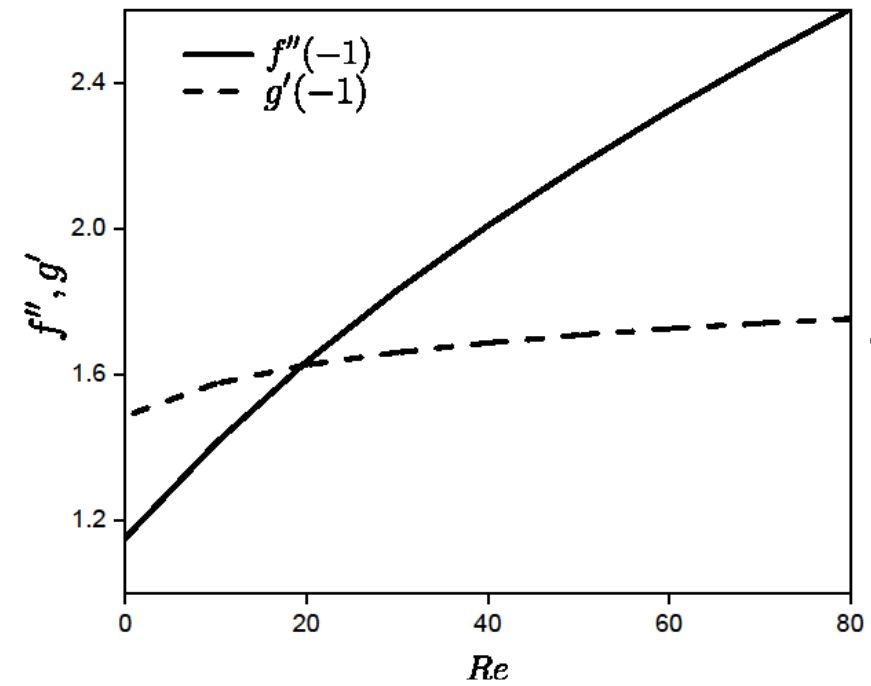

(a)

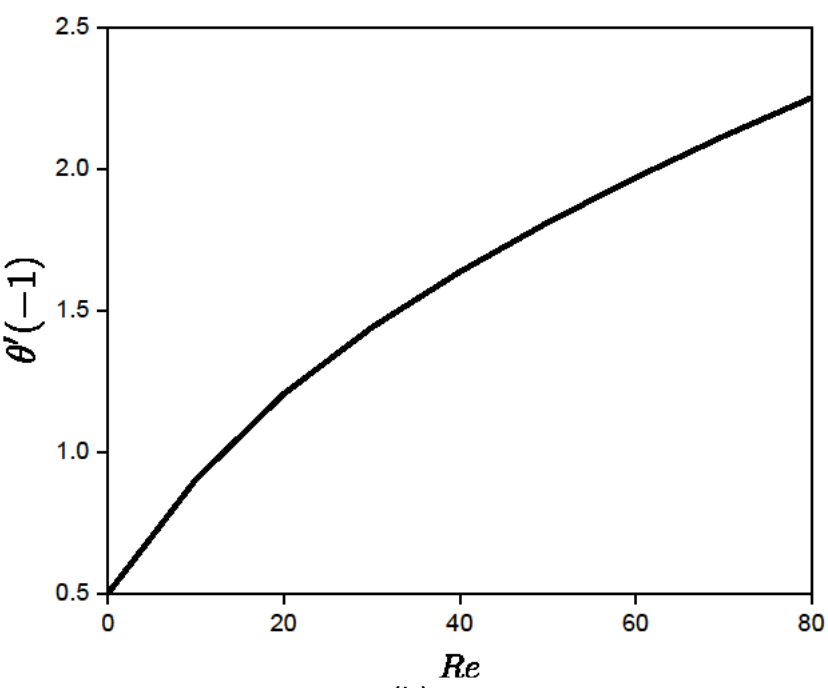

(b)

Fig. 6. (a) Shear and couple stresses and (b) Heat transfer rate at lower disk for various $\operatorname{Re}$ with $R=10, M=$ $0.5, \operatorname{Pr}=0.3$ and $\varphi=0.1$

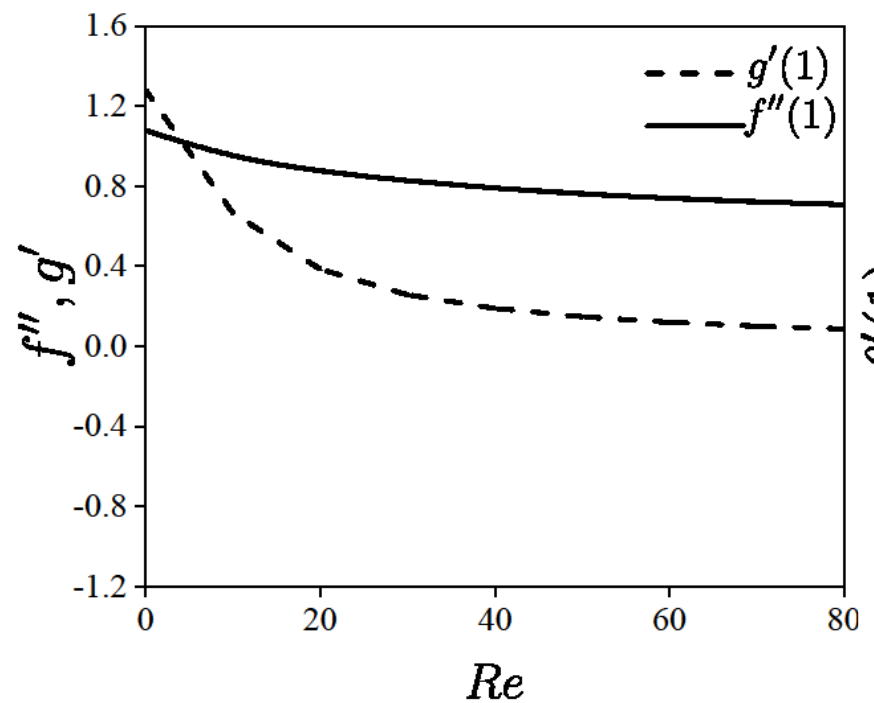

(a)

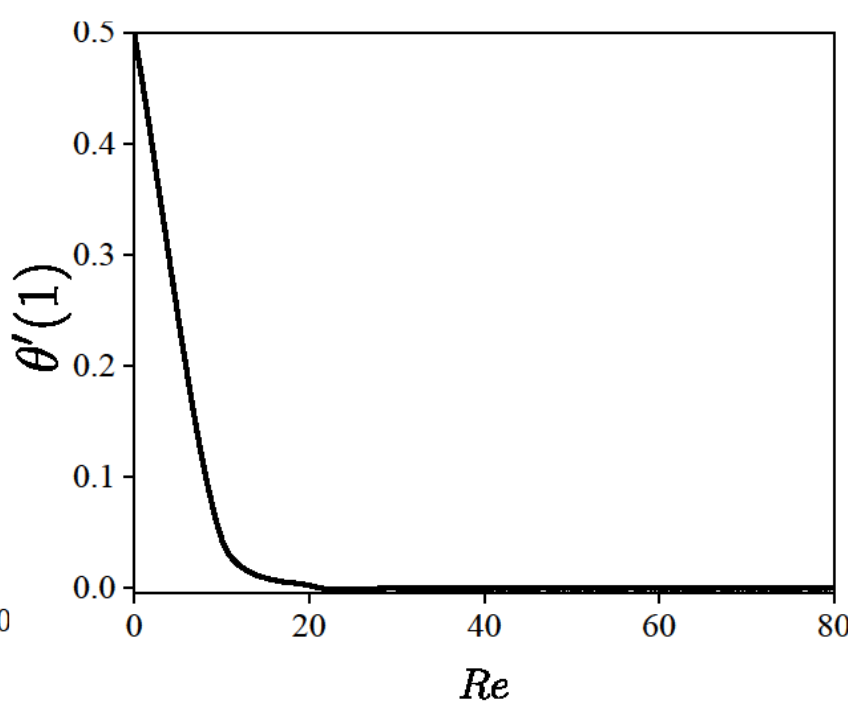

(b)

Fig. 7. (a) Shear and couple stresses and (b) Heat transfer rate at upper disk for various $R e$ with $R=10, M=$ $0.5, \operatorname{Pr}=0.3$ and $\varphi=0.1$

The variation of shear and couple stresses for varying micropolar parameter $R$ are plotted in Figure 8. It is noticed that the micropolar fluid reduces the shear stress and enhances the couple stress at the disk wall with an increase in $R$. This is in strong connections with the fact that micropolar fluids offering a great resistance due to the dynamic viscosity and vortex viscosity to the fluid motion as compared to Newtonian fluids. 


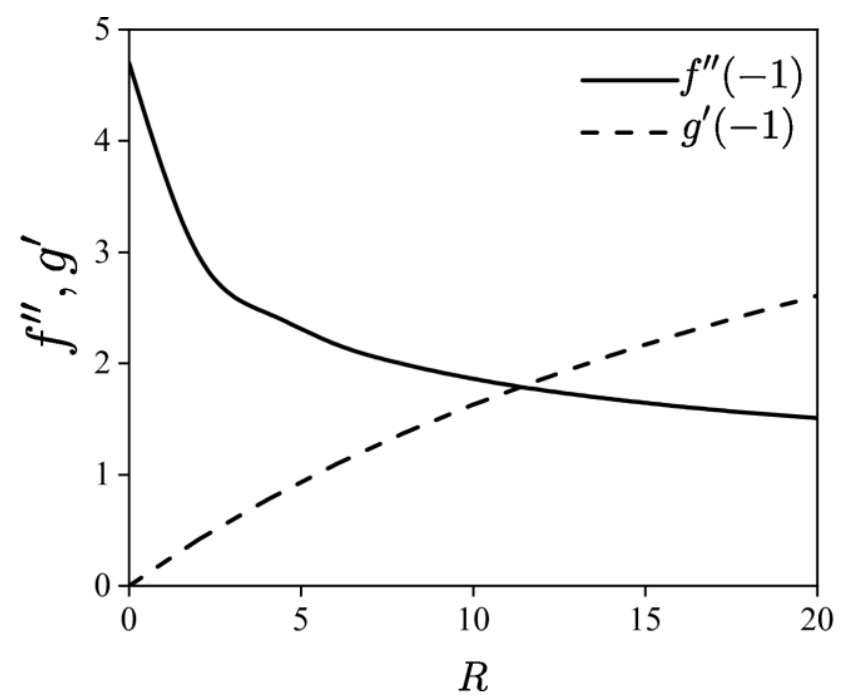

(a)

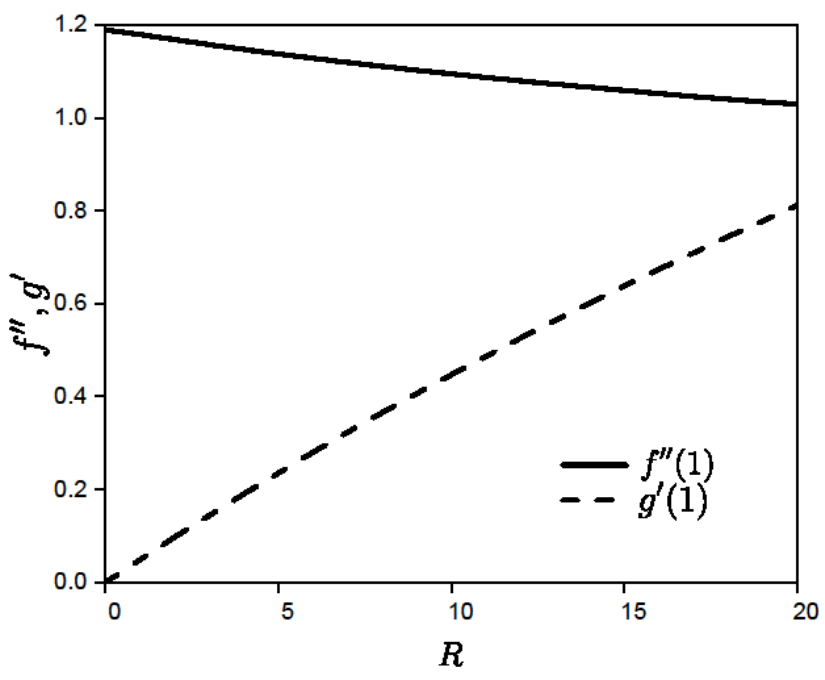

(b)

Fig. 8. Shear and couple stresses (a) at lower disk and (b) at upper disk for various $R$ with $R e=20, M=$ $1.5, \operatorname{Pr}=0.3$ and $\varphi=0.1$

From the Figure 9 and 10 it is evident that the presence of magnetic field enhances the shear stress, couple stress and heat transfer rate at the boundaries. Also it is apparent from Figure 11 that the heat transfer rate increases at the impermeable disk with an increase in Prandtl number $\operatorname{Pr}$ but decreases at the porous disk.

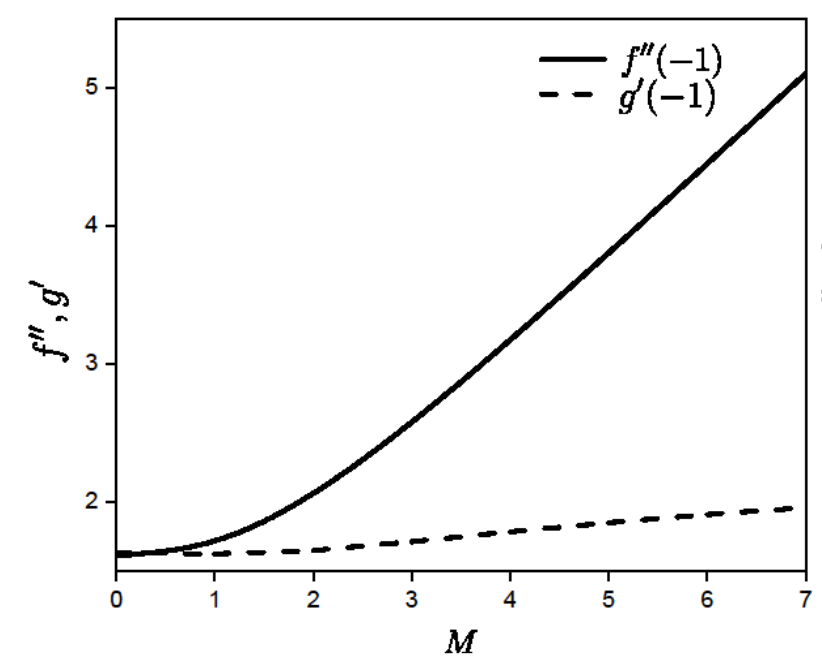

(a)

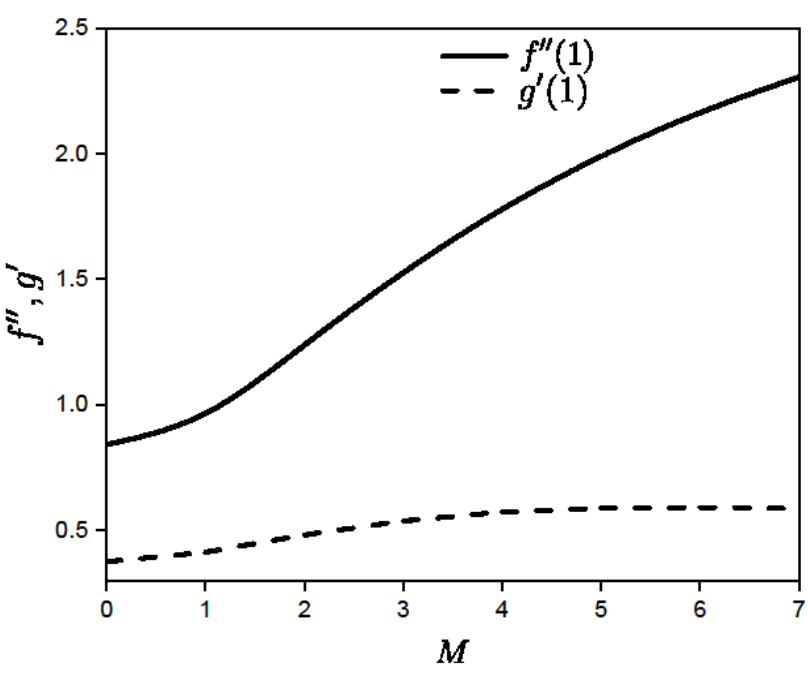

(b)

Fig. 9. Shear and couple stresses (a) at lower disk and (b) at upper disk for various $M$ with $R=10, \operatorname{Pr}=$ $0.2, \operatorname{Re}=20$ and $\varphi=0.1$ 


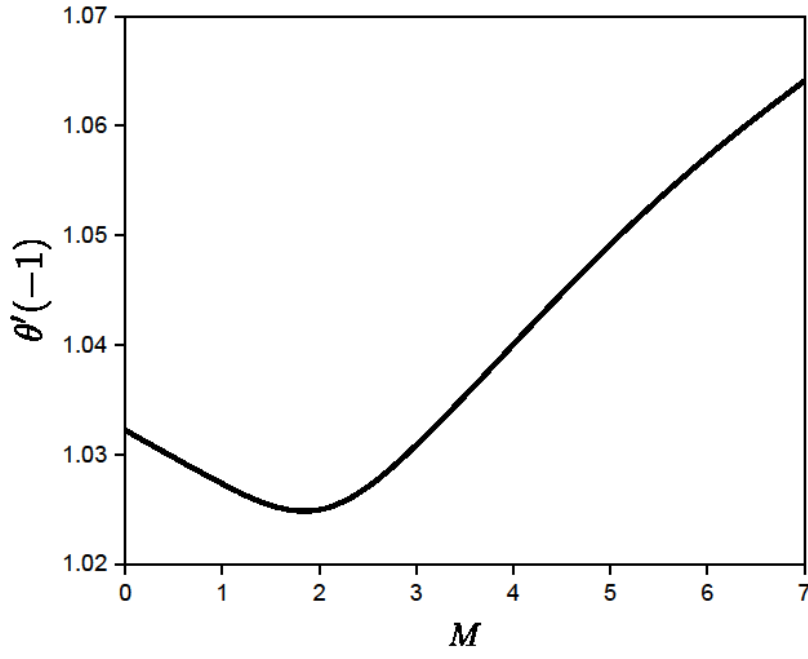

(a)

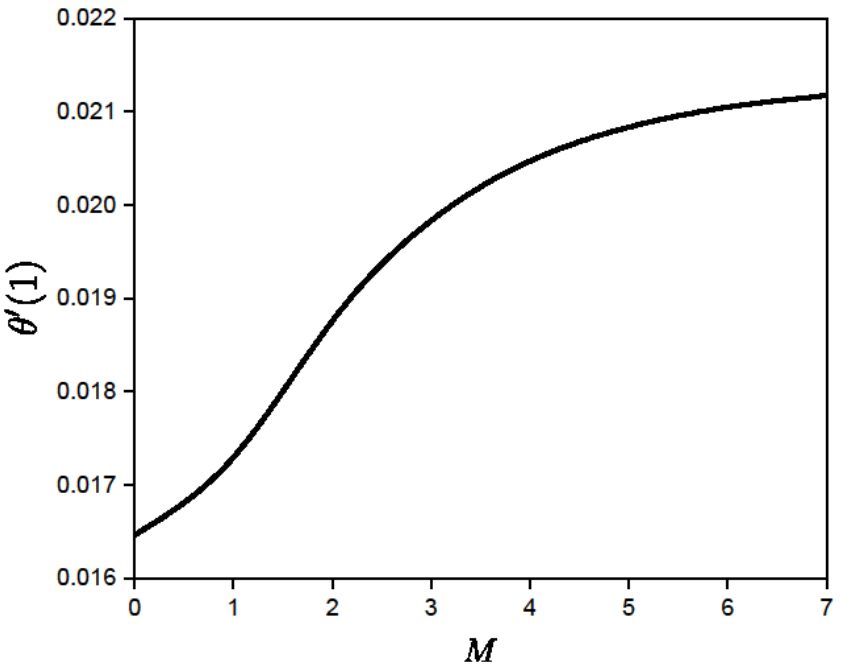

(b)

Fig. 10. Heat transfer rate (a) at lower disk and (b) at upper disk for various $M$ with $R=10, \operatorname{Pr}=0.2, \operatorname{Re}=$ 20 and $\varphi=0.1$

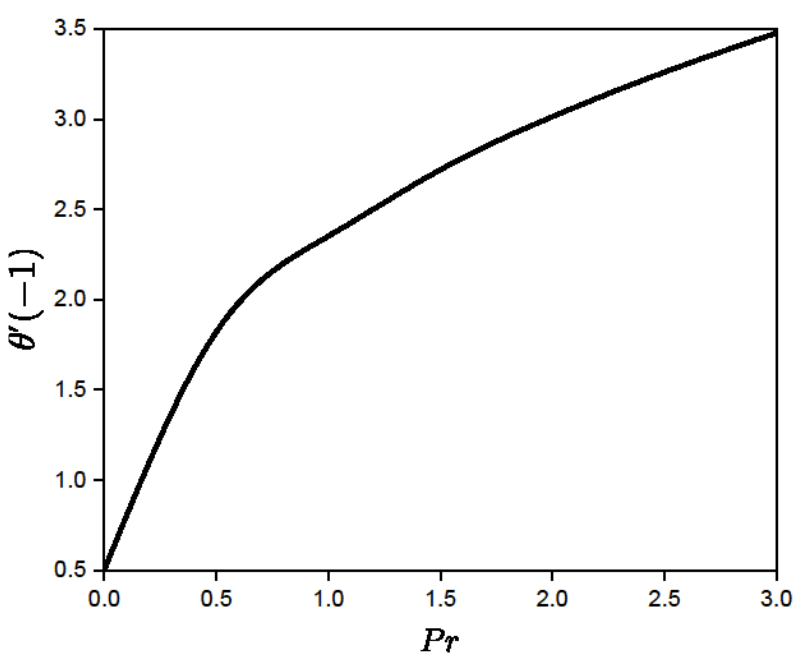

(a)

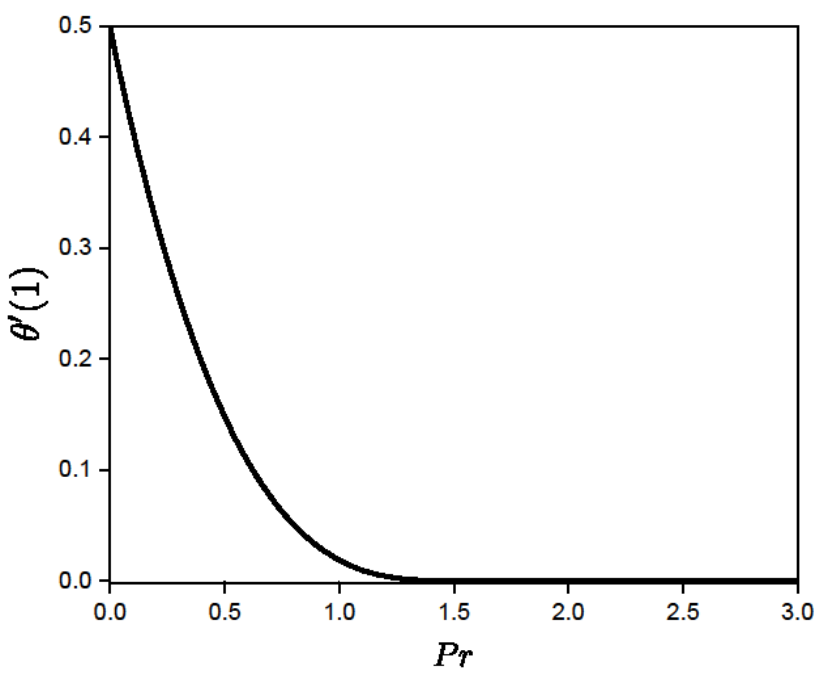

(b)

Fig. 11. Heat transfer rate (a) at lower disk and (b) at upper disk for various $\operatorname{Pr}$ with $R=5, M=$ $0.5, R e=30$ and $\phi=0.1$

\section{Conclusions}

The present study has investigated the effects of some governing parameters on the flow of an electrically conducting micropolar fluid in the presence of an applied magnetic field. Numerical solutions of the transformed self-similar governing equations and the associated boundary conditions have been obtained by using a finite-difference based Keller-box scheme. The conclusions can be summarized as follows.

i. The presence of slip at the porous boundary alters the flow. It decreases the axial velocity and increases the microrotation.

ii. Micropolar fluids reduce shear stress when compared to Newtonian fluids.

iii. The magnetic field is observed to have a positive effect on shear stress, couple stress, and heat transfer rate. 
iv. The Reynolds number has an obvious effect on velocity profiles. The increase in Reynolds number increases the magnitude of axial velocity. The magnitude of radial velocity is increased up to the central plane but decreased as it approaches the porous disk.

v. Microrotation profiles showed a decrease up to central plane with an increase in Reynolds number, a drastic increase with an increase in micropolar parameter, and also an enhanced profile near the porous disk with an increase in slip parameter.

vi. The suction Reynolds number increases the shear, couple stresses, and also heat transfer rate at the lower disk but decreases at the wall of the porous disk.

vii. Magnetic parameter enhances shear stress, couple stress, and heat transfer rate at the boundaries.

\section{References}

[1] Eringen, A. Cemal. "Theory of micropolar fluids." Journal of Mathematics and Mechanics (1966): 1-18.

https://doi.org/10.1512/iumj.1967.16.16001

[2] Ariman, T. M. A. N. D., M. A. Turk, and N. D. Sylvester. "Microcontinuum fluid mechanics-a review." International Journal of Engineering Science 11, no. 8 (1973): 905-930.

https://doi.org/10.1016/0020-7225(73)90038-4

[3] Ariman, T. T. N. D., M. A. Turk, and N. D. Sylvester. "Applications of microcontinuum fluid mechanics." International Journal of Engineering Science 12, no. 4 (1974): 273-293.

https://doi.org/10.1016/0020-7225(74)90059-7

[4] Guram, G. S., and M. Anwar. "Micropolar flow due to a rotating disc with suction and injection." ZAMM-Journal of Applied Mathematics and Mechanics/Zeitschrift für Angewandte Mathematik und Mechanik 61, no. 11 (1981): 589595.

https://doi.org/10.1002/zamm.19810611107

[5] Kelson, Neil A., and Andre Desseaux. "Effect of surface conditions on flow of a micropolar fluid driven by a porous stretching sheet." International Journal of Engineering Science 39, no. 16 (2001): 1881-1897.

https://doi.org/10.1016/S0020-7225(01)00026-X

[6] Kelson, Neil A., Andre Desseaux, and Troy W. Farrell. "Micropolar flow in a porous channel with high mass transfer." ANZIAM Journal 44 (2002): C479-C495.

https://doi.org/10.21914/anziamj.v44i0.692

[7] Lukaszewicz, Grzegorz. Micropolar fluids: theory and applications. Springer Science \& Business Media, 1999. https://doi.org/10.1007/978-1-4612-0641-5 5

[8] Moreau, René J. Magnetohydrodynamics. Vol. 3. Springer Science \& Business Media, 2013.

[9] Rudraiah, N. "Flow of a conducting fluid between porous disks for large suction Reynolds number." Journal of the Physical Society of Japan 27, no. 4 (1969): 1041-1045.

https://doi.org/10.1143/JPSJ.27.1041

[10] Attia, Hazem Ali, and N. A. Kotb. "MHD flow between two parallel plates with heat transfer." Acta mechanica 117, no. 1-4 (1996): 215-220.

https://doi.org/10.1007/BF01181049

[11] Rasmussen, Henning. "Steady viscous flow between two porous disks." Zeitschrift für angewandte Mathematik und Physik ZAMP 21, no. 2 (1970): 187-195.

https://doi.org/10.1007/BF01590643

[12] Elcrat, Alan R. "On the radial flow of a viscous fluid between porous disks." Archive for Rational Mechanics and Analysis 61, no. 1 (1976): 91-96. https://doi.org/10.1007/BF00251865

[13] Gaur, Y. N., and R. C. Chaudhary. "Heat transfer for laminar flow through parallel porous disks of different permeability." In Proceedings of the Indian Academy of Sciences-Mathematical Sciences, vol. 87, no. 9, pp. 209-217. Springer India, 1978. https://doi.org/10.1007/BF02837756

[14] Guram, G. S., and M. Anwar. "Steady flow of a micropolar fluid due to a rotating disc." Journal of Engineering Mathematics 13, no. 3 (1979): 223-234. https://doi.org/10.1007/BF00036671 
[15] Takhar, Harmindar S., R. Bhargava, R. S. Agrawal, and A. V. S. Balaji. "Finite element solution of micropolar fluid flow and heat transfer between two porous discs." International journal of engineering science 38, no. 17 (2000): 1907-1922.

https://doi.org/10.1016/S0020-7225(00)00019-7

[16] Ashraf, Muhammad, M. Anwar Kamal, and K. S. Syed. "Numerical study of asymmetric laminar flow of micropolar fluids in a porous channel." Computers \& Fluids 38, no. 10 (2009): 1895-1902. https://doi.org/10.1016/i.compfluid.2009.04.009

[17] Ashraf, M., and A. R. Wehgal. "MHD flow and heat transfer of micropolar fluid between two porous disks." Applied mathematics and mechanics 33, no. 1 (2012): 51-64. https://doi.org/10.1007/s10483-012-1533-6

[18] Si, Xin-hui, Lian-cun Zheng, Xin-xin Zhang, and Xin-yi Si. "Flow of micropolar fluid between two orthogonally moving porous disks." Applied Mathematics and Mechanics 33, no. 8 (2012): 963-974. https://doi.org/10.1007/s10483-012-1598-8

[19] Vatani, M., S. E. Ghasemi, and D. D. Ganji. "Investigation of micropolar fluid flow between a porous disk and a nonporous disk using efficient computational technique." Proceedings of the Institution of Mechanical Engineers, Part E: Journal of Process Mechanical Engineering 230, no. 6 (2016): 413-424. https://doi.org/10.1177/0954408914557375

[20] Valipour, P., S. E. Ghasemi, and M. Vatani. "Theoretical investigation of micropolar fluid flow between two porous disks." Journal of Central South University 22, no. 7 (2015): 2825-2832. https://doi.org/10.1007/s11771-015-2814-1

[21] Hasnain, Jafar, and Zaheer Abbas. "Entropy generation analysis on two-phase micropolar nanofluids flow in an inclined channel with convective heat transfer." Thermal Science 23, no. 3 Part B (2019): 1765-1777. https://doi.org/10.2298/TSCl170715221H

[22] Abbas, Zaheer, Muhammad Asif Jafar, and Jafar Hasnain. "Analysis of asymptotic solutions for non-Newtonian fluid flow between two parallel discs with dissimilar in-plane motion." European Journal of Mechanics-B/Fluids (2020). https://doi.org/10.1016/i.euromechflu.2020.06.002

[23] Beavers, Gordon S., and Daniel D. Joseph. "Boundary conditions at a naturally permeable wall." Journal of fluid mechanics 30, no. 1 (1967): 197-207. https://doi.org/10.1017/S0022112067001375

[24] Saffman, Philip Geoffrey. "On the boundary condition at the surface of a porous medium." Studies in applied mathematics 50, no. 2 (1971): 93-101. https://doi.org/10.1002/sapm197150293

[25] Abbas, Zaheer, Muhammad Asif Jafar, and Jafar Hasnain. "Asymptotic analysis of MHD viscous fluid flow due to a rotating disc and a radially stretching-shrinking disc with Navier slip condition." Physica Scripta 95, no. 2 (2019): 025204.

https://doi.org/10.1088/1402-4896/ab41dd

[26] Abbas, Zaheer, Sifat Hussain, Muhammad Y. Rafiq, and Jafar Hasnain. "Oscillatory slip flow of Fe3O4 and Al2O3 nanoparticles in a vertical porous channel using Darcy's law with thermal radiation." Heat Transfer.

[27] Wahid, Nur Syahirah, Mohd Ezad Hafidz Hafidzuddin, Norihan Md Arifin, Mustafa Turkyilmazoglu, and Nor Aliza Abd Rahmin. "Magnetohydrodynamic (MHD) Slip Darcy Flow of Viscoelastic Fluid Over A Stretching Sheet and Heat Transfer with Thermal Radiation and Viscous Dissipation." CFD Letters 12, no. 1 (2020): 1-12.

[28] Keller, Herbert B. "A new difference scheme for parabolic problems." In Numerical Solution of Partial Differential Equations-II, pp. 327-350. Academic Press, 1971. https://doi.org/10.1016/B978-0-12-358502-8.50014-1

[29] Keller, Herbert B. "Some computational problems in boundary-layer flows." In Proceedings of the Fourth International Conference on Numerical Methods in Fluid Dynamics, pp. 1-21. Springer, Berlin, Heidelberg, 1975. https://doi.org/10.1007/BFb0019723

[30] Keller, Herbert B. "Numerical methods in boundary-layer theory." Annual Review of Fluid Mechanics 10, no. 1 (1978): 417-433. https://doi.org/10.1146/annurev.fl.10.010178.002221

[31] Vajravelu, Kuppalapalle, and Kerehalli V. Prasad. Keller-box method and its application. Vol. 8. Walter de Gruyter GmbH \& Co KG, 2014. https://doi.org/10.1515/9783110271782

[32] Kármán, Th V. "Über laminare und turbulente Reibung." ZAMM-Journal of Applied Mathematics and Mechanics/Zeitschrift für Angewandte Mathematik und Mechanik 1, no. 4 (1921): 233-252. https://doi.org/10.1002/zamm.19210010401 
[33] Bhat, Ashwini, and Nagaraj N. Katagi. "Micropolar fluid flow between a non-porous disk and a porous disk with slip: Keller-box solution." Ain Shams Engineering Journal 11, no. 1 (2020): 149-159.

https://doi.org/10.1016/i.asej.2019.07.006

[34] Ashraf, Muhammad, M. Anwar Kamal, and K. S. Syed. "Numerical simulation of flow of a micropolar fluid between a porous disk and a non-porous disk." Applied Mathematical Modelling 33, no. 4 (2009): 1933-1943. https://doi.org/10.1016/i.apm.2008.05.002 